\title{
METHODOLOGY TO GENERATE NAVIGATION MODELS IN BUILDING
}

\author{
Elżbieta LEWANDOWICZ ${ }^{1^{*}}$, Przemysław LISOWSKI ${ }^{2}$ (]) \\ ${ }^{1}$ Faculty of Geodesy, Geospatial and Civil Engineering, University of Warmia and Mazury in Olsztyn, Poland, \\ ${ }^{2}$ Department of Geoinfirmatics and Applied Computer Science, Faculty of Geology, Geophysics and \\ Environmental Protection, AGH University of Science and Technology, Krakow, Poland
}

Received 06 March 2018; accepted 28 September 2018

\begin{abstract}
Indoor route networks models are created for use in navigation. They may be built manually, but it is better to generate them automatically, based on the building floor plans. Research has been conducted in this field in many research centers. The authors undertook to develop their own methodology for generating navigation networks, using topological neighborhood relations and semantic data. The research project focuses on one floor in a building, which consists of rooms and an expanded corridor with an obstacle in the form of an open space between the floors. The first stage of the project consisted in the segmentation of the corridor space to improve its resolution. The objective of the conducted research was to select special points (five suggestions) for the segmentation. As a result, five different segmentations of the corridor space were obtained. The aim of the second stage was to automatically generate five navigation network models. The graphically presented results have been verified against the routes generated between the selected points in the building plan. A comparison of the results with other solutions shows that the routes generated in the presented methodology are more straight-line and less zigzagging.
\end{abstract}

Keywords: indoor navigation, navigation routes in buildings, TIN, Voronoi, segmentation hallway.

\section{Introduction}

Indoor navigation complements GPS navigation which is not available in buildings (Hilsenbeck et al. 2014; Gao et al. 2017). It requires a model of a navigation network (Coleman et al. 2016; Boeters et al. 2015), which allows setting footpaths or emergency routes. Such models, in the form of navigation route presentations, are commonly used in their analogue form on notice boards and commercial leaflets. In the digital age, navigation in buildings is increasingly implemented with the use of mobile applications. In this technology, the process of navigation based on network models saved in the mathematical structures of a graph plays an important role. The models should reflect the natural flow of individuals inside buildings.

Research work has been done on the automatic process of generating navigation network models, based on building plans. Different solutions have been offered in the relevant literature, based on well-described methodologies. Some of them rely on simple topological relations (Figure 1a), based on the neighborhood (Tang et al. 2015; Lewandowicz 2015). Lee (2004) proposed a modified topological model from a Graph Nod Relations Structure
(NRS) to a navigation network model (Figure $1 \mathrm{~b})$. He used the medial axis transformation (MAT) algorithm (Prinz, Cern 1988; Joan-Arinyo et al. 1997). The MAT algorithm is also applied in other presented solutions (Teo, Cho 2016) (Figure 2).

Other solutions based on topological, semantic and geometric relations (Stoffel et al. 2007; Whiting 2006; Zhu et al. 2016; Lewandowicz 2014, 2015). In those cases, the type of rooms and entries are considered (Figure 3). Other network generating solutions are based on the Triangulated Irregular Network (TIN) models (Xu et al. 2016a). Selected points from the tested space (entrances, refracted walls) form the basis for creating TIN (Figure 4). Krūminaitè (2014) and Mortari et al. (2014) proposed a modification of the TIN network by increasing density. Krūminaite (2014) used polygon TIN for segmentation spaces by combining the means of neighboring polygons of TIN. Bogusławski et al. (2016) used Voronoi Diagrams for a segmentation hallway. They generated a network and combined the means of neighboring polygons (Voronoi Diagram) (Figure 5). In this way, the polylines are defined,

*Corresponding author. E-mail: leela@uwm.edu.pl 

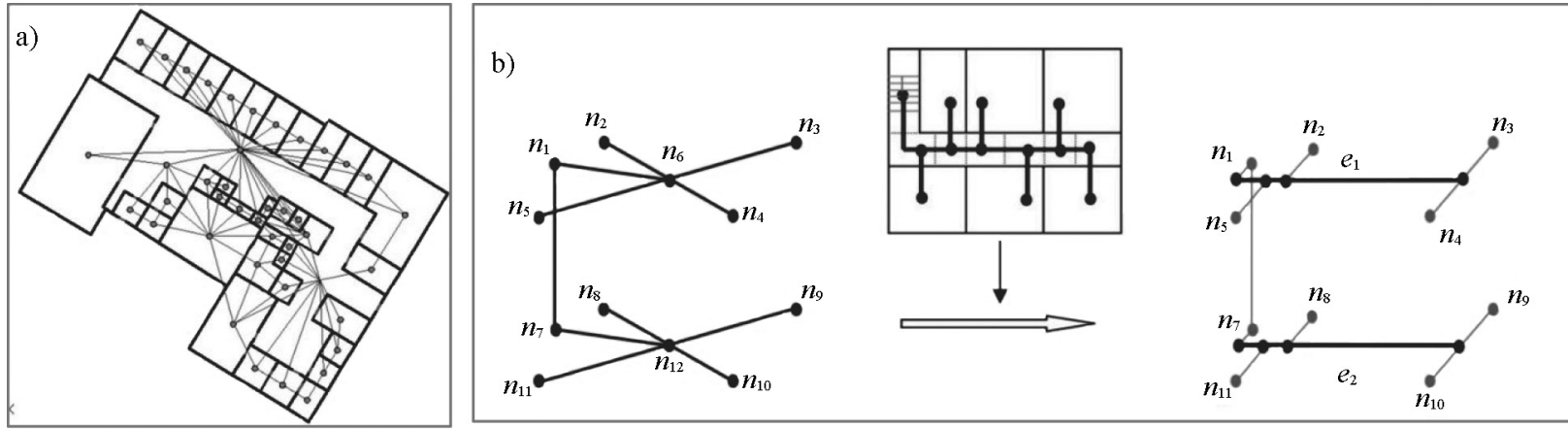

Figure 1. Network model based on the relationship topological neighborhood structures (NRS): a) graphNod Relations Structure (NRS) (Lewandowicz 2015); b) transformation of the model NRS to a navigation network model (Lee 2004)
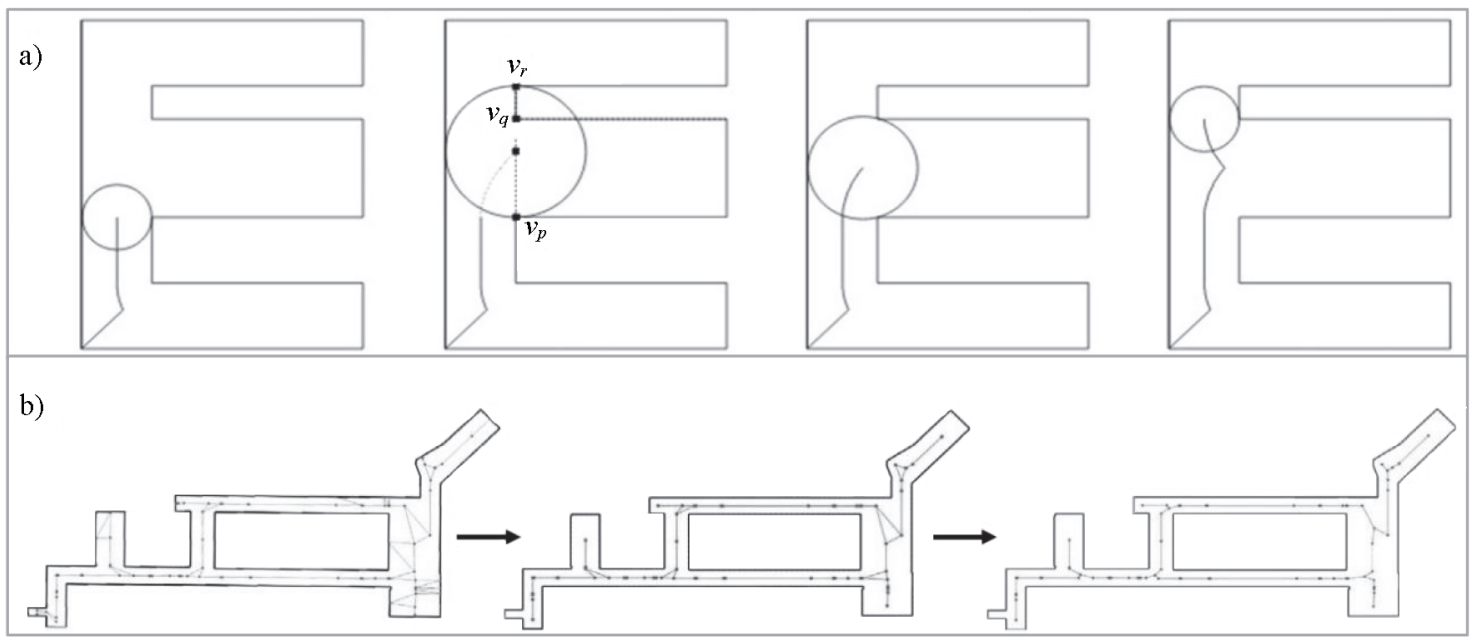

Figure 2. The principle of applying the MAT algorithm to establish an axis in indoor navigation: a) the principle of the MAT algorithm (Joan-Arinyo et al. 1997); b) optimization of networks generated with MAT (Teo, Cho 2016)

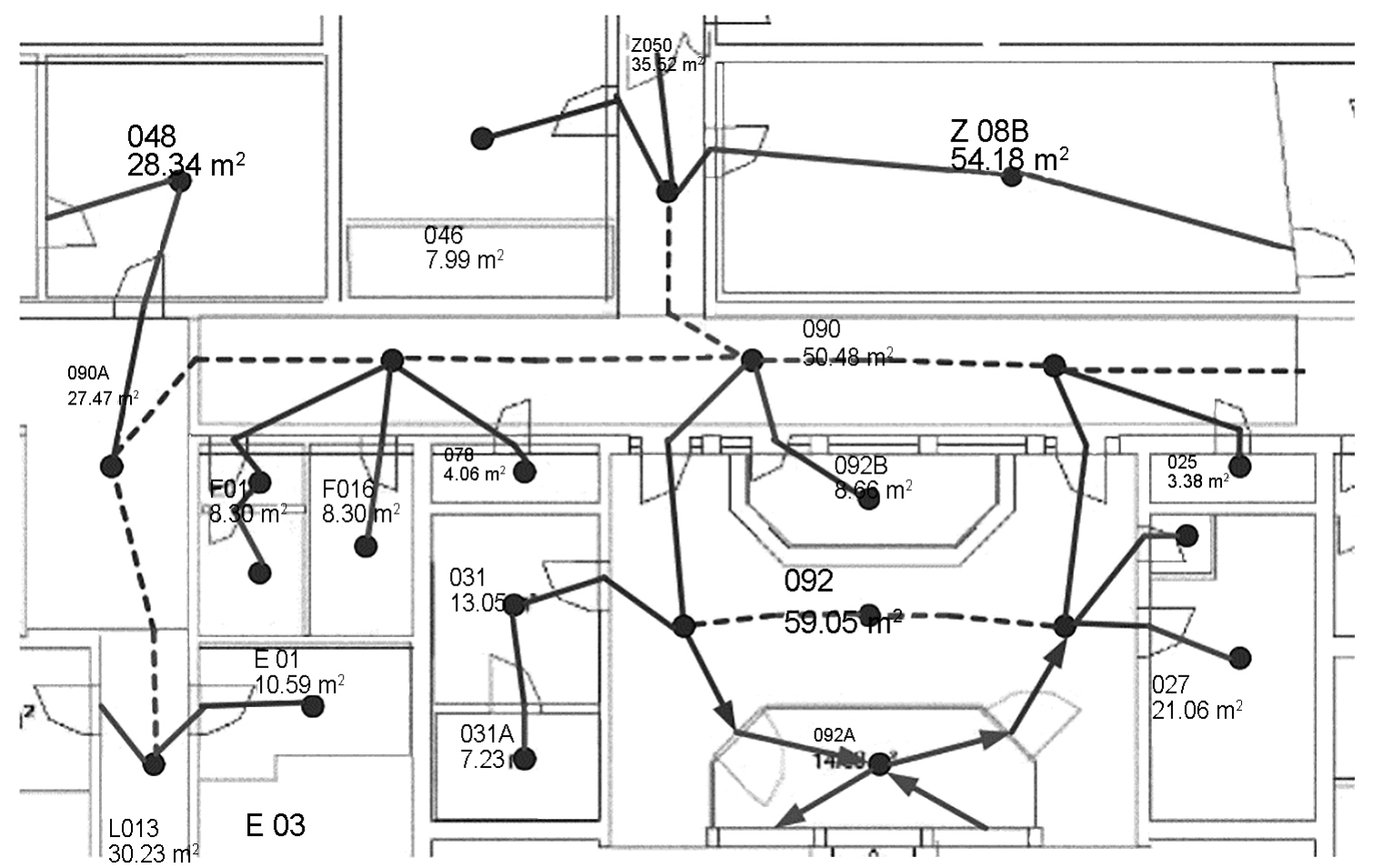

Figure 3. Cell centers and paths overlaid with a floor Plan (Stoffel et al. 2007) 

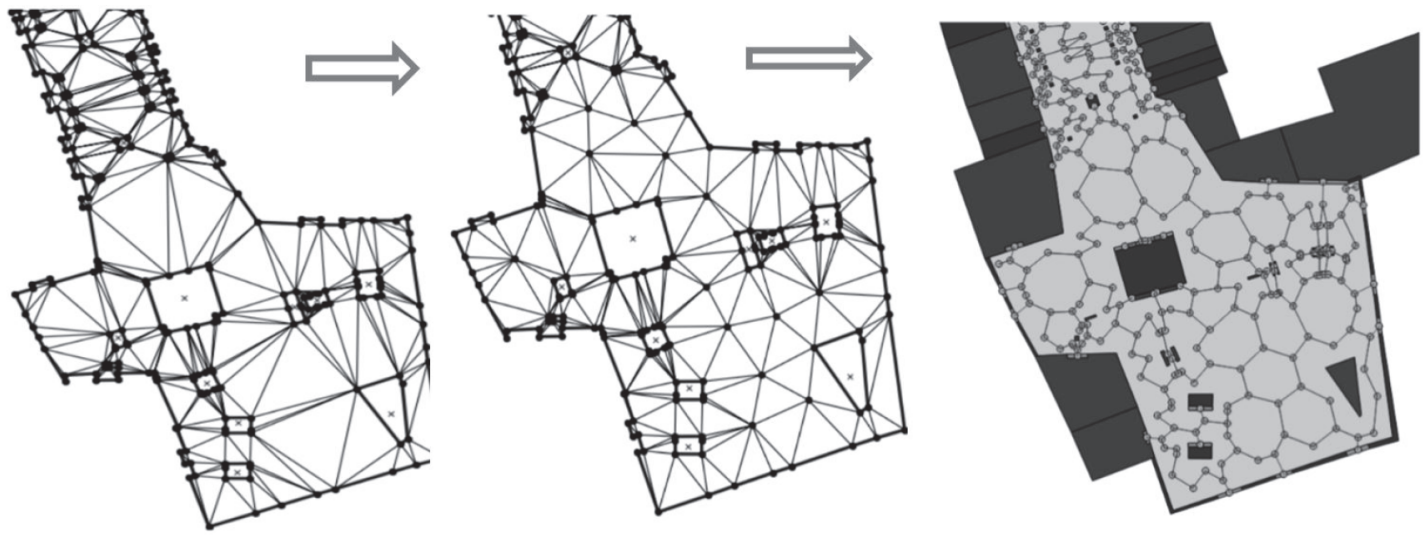

Figure 4. Construction of navigation network based on TIN by connections of central points of neighboring polygons of TIN (Krūminaite 2014)

often zigzagging, which must be simplified. Other hybrid solutions (Lin et al. 2017; Afyouni et al. 2012) combined topological relations with GRID models. These solutions segment the space into regular high-resolution grids. The processing time of the data necessary to obtain a network can be very elongated (Franz et al. 2005).

The algorithms are also related to interpolation using Thiessen Polygons (called Voronoi Diagrams) (Brassel, Reif 1979; Hilsenbeck et al. 2014). Wallgrün (2004) proposes to create a navigation network based on simplified lines of the diagram Voronoi (Figure 6).

Bogusławski et al. (2016) postulates an automatic generation of navigation networks, of diverse modified resolution, depending on the needs. Despite the many proposed solutions (Liu, Zlatanova 2015), work is still being done to develop new, better methodologies (Staats et al. 2017; Yan et al. 2018; Yang et al. 2017; Yang, Worboys 2015; Alattas et al. 2017; Teo, Cho 2016). New opportunities are being sought for modelling navigation networks inside furnished spaces (Xu et al. 2016a), as well as applications, e.g. for emergency (rescue) actions (Lee 2007; Bogusławski et al. 2016; Lin et al. 2017; Cichociński 2017; Xu et al. 2016b). All solutions are assumed to simulate natural navigation routes. A natural route does not contain right and sharp angles and does not pass near walls. In addition, they should strive to minimize the processing time of the input data in the network generation, as well as minimize
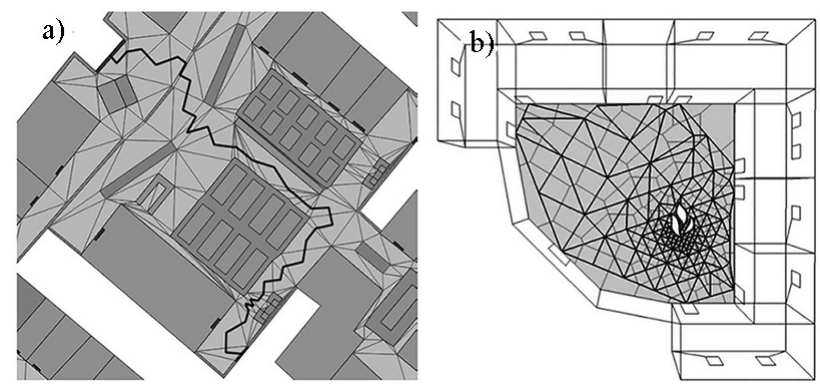

Figure 5. Navigation models based on topological data from segmentations hallway: a) polygon TIN segmentation space (Krūminaitè 2014); b) Voronoi Diagram segmentation space (Bogusławski et al. 2016) the time of generating routes to various users. A comparison of results of various algorithms (analytical methods) is conducted to find the optimal solution (Hahmann et al. 2018).

\section{Research objective and methodology}

This work is a continuation of the research previously undertaken by the author (Lewandowicz 2014, 2015) on the automatic generation of indoor navigation routes (Figure 7), based on topological and semantic relations. Those studies relied on centroids of the spaces (rooms, corridors) and took into account the centroids of entries - door passages. As with other researchers (Stoffel et al. 2007; Whiting 2006), the produced solutions did not reflect the natural routes in public navigation spaces - corridors (Figures 3 and 7). The designated network routes in corridors contain sharp angles.

The aim of the study is to continue the research on the automatic generation of the navigation network in the building. The authors have solved the problem of generating networks in the corridor's space. The objective of the ongoing research is to build models of navigation networks of higher resolution. Topological and semantic relations have been assumed to be the basis for the generation of navigation network models (Lewandowicz et al. 2013). However, before they can be used for construction of a)

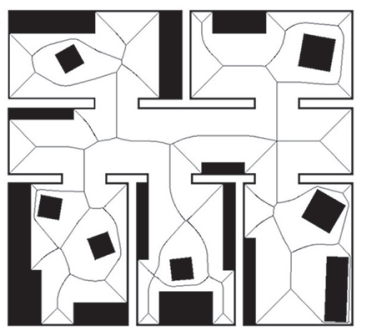

b)

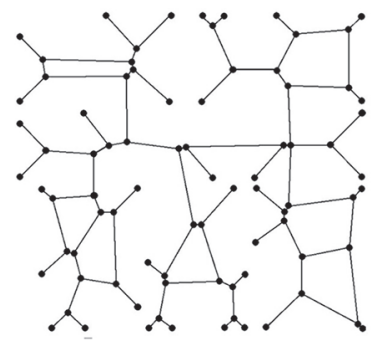

Figure 6. Modeling of the navigation network based on the Voronoi diagram: a) modeling Voronoi-based route graph;

b) generalized Voronoi graph (Wallgrün 2004) 

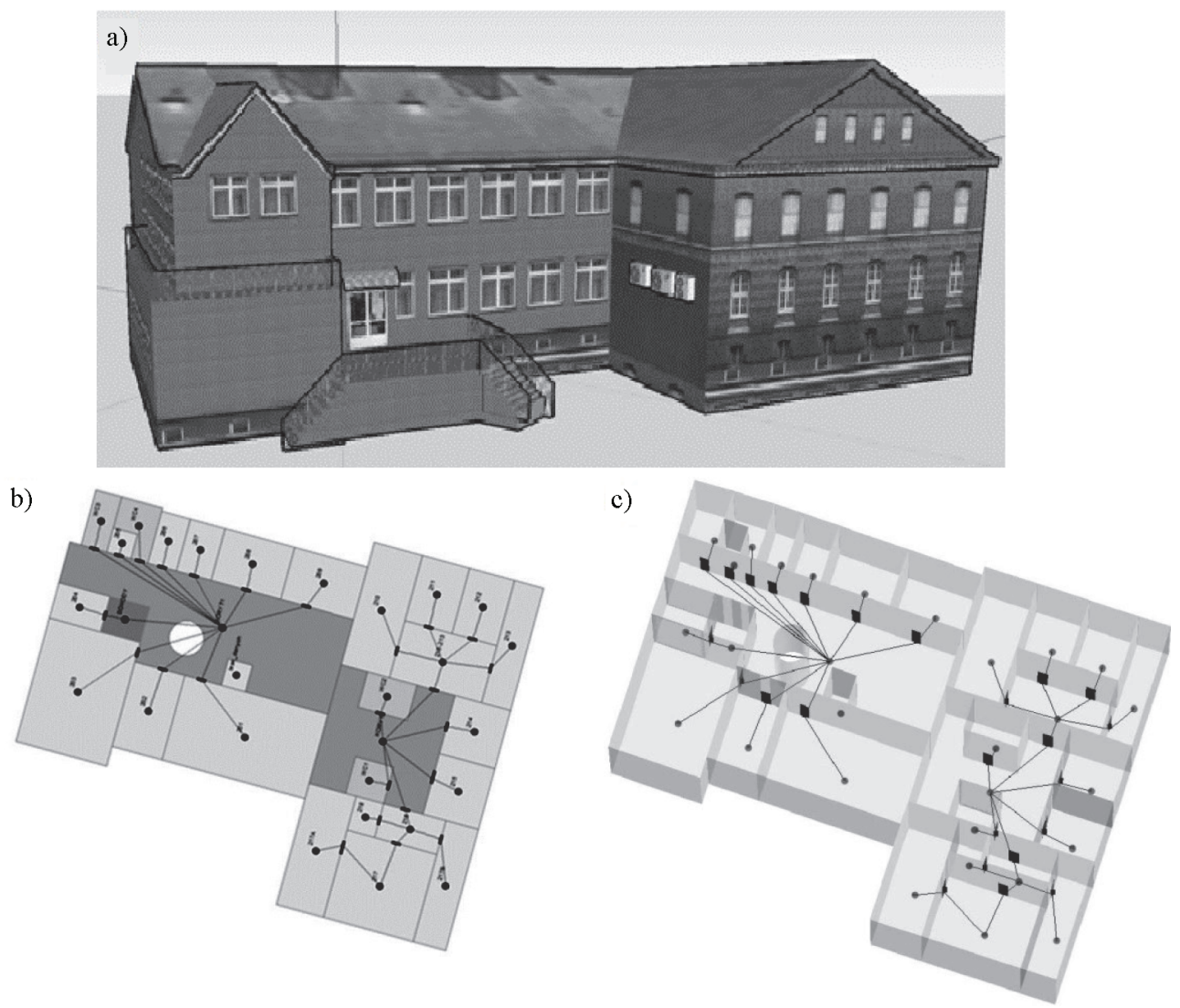

Figure 7. Research object: a) building (Kaliszczuk 2013); b) floor 2 network model based on topological and semantic relations on the basis of centroids in 2D image; c) isometric view (Lewandowicz 2014, 2015)

network models, public navigation passages (corridors) will be segmented into sub-spaces. The score of the segmentation of the public space will be done by evaluating the generated models of navigation networks. The generated routes should not be zigzagging and should not contain sharp or straight angles.

Figure 8 shows the research object, in the form of the first-floor plan in the presented building (Figure 7). The plan details rooms, the corridor, elevator, stairs and room entries and barriers and an open space between the two floors. The expanded space of the corridor allows for the opportunity of testing various methodologies for public space segmentation. The results will be verified against the automatic generated exemplary route (Figure $8 \mathrm{~b}$ ).

It is assumed that the solution should be possible by using the Geographic Information System (GIS), e.g. software ArcGIS of the Environmental Systems Research Institute (ESRI 2018) and the author's application "Cgraph" (Lisowski, Lewandowicz 2018), prepared for PC-class computers containing GDAL and Neo4jdriver. Building
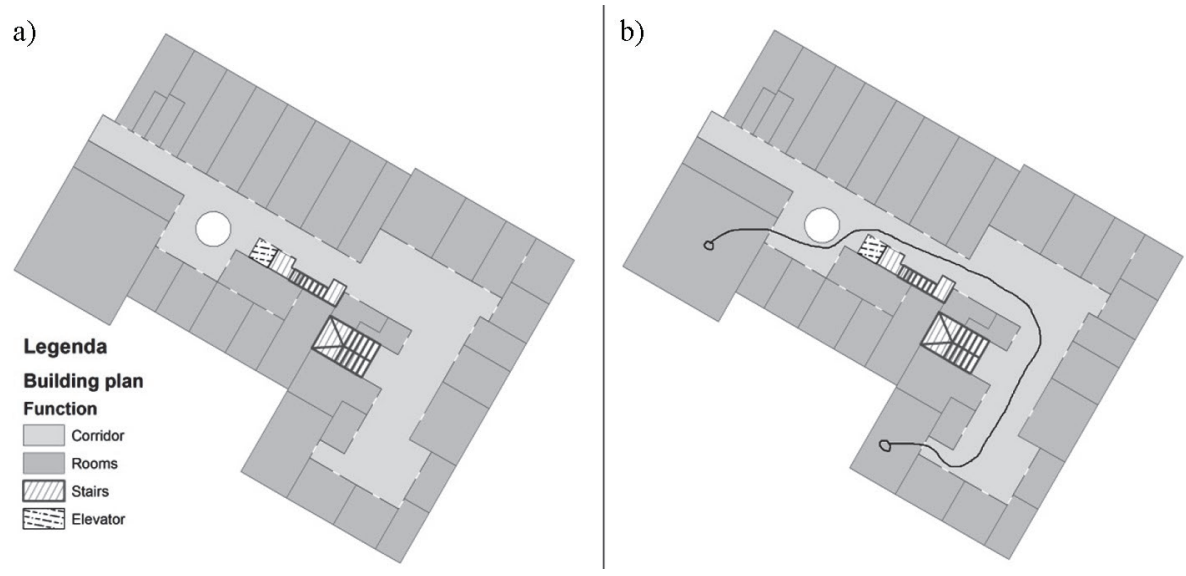

Figure 8. The research object. In the corridor is the open space between the two floors, shown by a white circle, showing: a) floor and building plan; b) the route between two points, as a proposal to verify the results from generating the shortest route 
plans made in 3d CAD can be imported into GIS (Lewandowicz 2015). The GIS provides spatial data processing tools and the generation of TIN and Polygonal Thiessena (Voronoi). Using these tools, the authors performed the segmentation of public space. The Cgraph application generated network models from the segmentation space. In the GIS application, the authors performed a network analysis.

The authors performed segmentation based on the GIS tools, using algorithms for the construction of TIN - Constrain Delaunay Triangulation (Chew 1987) and Voronoi Diagram (Thiessen Polygon) (Wei et al. 2012; ESRI 2018). The topological network model generation was made in the Cgraph application. The network was built based on the topological neighborhood relation, taking advantage of the attributes describing the function of the rooms (the corridor, rooms, stairs, entries, and the elevator). The network models were then applied to the GIS application. Generation of the shortest routes was done in ArcGIS (ESRI 2018). The network analysis tools use Dijkstra's algorithm. The costs of the route were determined by the length of route sections.

The elaborate processing algorithm for corridor segmentation is described below. It takes into account the total space of the object $S_{\text {Whole }}$ and distinguishes corridor space $S_{\text {Corridor }}$ and other usable space $S_{\text {Use }}$ (Eqn (1)). The algorithm also emphasizes the functional space of the corridor $S_{C F}$ (Eqn (2)). This is a space limited to the middle of the corridor, away from walls, e.g. 0.7-1 m. Krūminaitè (2014) in her studies determined a functional space near different objects. The value of $1 \mathrm{~m}$ can be assumed to be optimal.

$$
\begin{aligned}
& \mathrm{S}_{\text {Whole }}=\mathrm{S}_{\text {Corridor }} \mathrm{S}_{\text {Use }} ; \\
& \mathrm{S}_{\mathrm{CF}}<\mathrm{S}_{\text {Corridor }}
\end{aligned}
$$

The basis for segmentation of corridor space will be a set of base points $\{P\}$.

The authors put forward the thesis that the selection of $P$ points affects segmentation and the shape of the generated network. They assumed that the $\{P\}$ set have been used as: entry points to the rooms $\{E\}$, vertices of partition walls $\{W\}$, means of the partition wall lines $\{C\}$. When setting up the experiment, they wanted to check how a selection of base points affects the results of segmentation and a model of the generated network. The experiment results are supposed to allow for determination of the optimum set of base points.

The study adopted five subsets of the base points $\left\{P_{i}\right\}$, $i=1,2,3,4,5$, selected from the set $\{P\}(\operatorname{Eqn}(3))$ :

$$
P_{i} \subset P .
$$

It is known that various segmentations of the public space follow from various selection subset $P_{i}$ (Eqn (3)). The number of selected points accepted for the analysis influences the resolution of segmentation. With a small number of points, it will be smaller, and with a large set of base points, the segmentation will be larger. What choices are optimal? In carrying out the research objective, five tests were performed based on various subsets: $P_{1}, P_{2}, P_{3}$, $P_{4}, P_{5}$. In each test, a $P_{i}$ data set was determined according to the following criteria:

- Test 1 - only room entry points were selected, $P_{1}=\{E\}$

- Test 2 - the apex points on partition walls were selected, $P_{2}=\{W\}$;

- Test 3 - center room entry points and apex points on partition walls were selected, $P_{3}=(\{E\} \cup\{W\})$;

- Test 4 - center of walls (polylines) were selected, $P_{4}=\{C\}$;

- Test 5 - room entry points, medium points of walls and apex points on partition walls were selected, $P_{5}=(\{E\} \cup\{C\} \cup\{W\})$.

The collection of points $\{E\},\{W\},\{C\}$ was obtained from digital floor plans.

Data processing was performed according to the algorithm, as shown below.

Based on $P_{i}$, TIN was generated (Eqn (4)):

$$
P_{i} \stackrel{\text { generate }}{\rightarrow}(\text { TIN }) \text {. }
$$

The TIN polygon was converted to TIN edges (Eqn (5)):

$$
(T I N) \stackrel{\text { conversion }}{\rightarrow}\{E D G E\}_{(T I N)}
$$

The fragments of TIN edges, located in the functional space of the $S_{C F}$ corridor from the $\{E D G E\}_{T I N}$ were selected (Eqn (6)):

$$
\{E D G E\} \cap S_{C F}=\{E D G E\}_{\text {Selection and cut }} .
$$

From set $\{E D G E\}_{\text {Selectionand cut }}$ a set of centre points $\left\{P_{V}\right\}$ was generated (Eqn (7)):

$$
\left.\{E D G E\}_{\text {Selection and cut }}^{\text {generate line center point }} \rightarrow P_{V}\right\} .
$$

The set $\left\{P_{V}\right\}$ was the basis for creating the set of Theisen Polygons $\{$ Voronoi $\}$ (Eqn (8)):

$$
\left.\left\{P_{V}\right\}^{\text {generate Poligon Voronoi }} \rightarrow \text { Vorono }\right\}
$$

The collection $\{$ Voronoi\} had to be cut to the surface of the corridor $S_{\text {Coridor: }}$ :

$$
\{\text { Voronoi }\} \cap S_{\text {Corridor }}=\left\{\text { Voronoi }_{\text {Corridor }}\right\} .
$$

The collection of polygons $\left\{\right.$ Voronoi $\left._{\text {Corridor }}\right\}$ is the result of segmentation of the public space (corridor).

It must be connected to the output set $S_{\text {Whole }}$. The surfaces of the corridor $S_{\text {Corridor }}$ should be replaced with a collection of polygon $\{\text { Vorono } i\}_{\text {Corridor }}$. This can be done by combining:

$$
\left(\left\{S_{U s e}\right\} \cup\left\{\text { Voronoi }_{\text {Corridor }}\right\}\right)=S_{\text {Whole }}^{\text {New }} .
$$

$S_{W h o l e}^{\text {New }}$ is a collection of new polygons showing a floor plan with the segmentation of public space.

The polygons $S_{W h o l e}^{\text {New }}$ described by attributes are the basis for the generated navigation network. They are cre- 
ated based on topological and semantic relations. It is carried out by analogy, as in the work by Stoffel et al. (2007), Whiting (2006), Lewandowicz (2015). The authors use an in-house application to generate networks (Lisowski, Lewandowcz 2016, 2018). By generating the topological, semantic model of the road network, neighborhood relations were used:

$$
\begin{aligned}
& \text { - }\left(\left\{N O D_{\text {Vorono }_{\text {Coridor }}}\right\} \text { to }\left\{N O D_{\text {Voronoi }_{\text {Coridor }}}\right\}\right) \text {, } \\
& \text { - }\left(\left\{N O D_{\text {Voronoi }_{\text {Coridor }}}\right\} \text { to }\left\{\text { NOD }_{\text {Stair }}\right\}\right) \text {, } \\
& \text { - }\left(\left\{\text { NOD }_{\text {Voronoi }_{\text {Coridor }}}\right\} \text { to }\left\{N O D_{\text {Elavator }}\right\}\right) \text {, } \\
& \text { - }\left(\left\{N O D_{\text {Voronoi }_{\text {Coridor }}}\right\} \text { to }\left\{N O D_{E}\right\}\right) \text {, } \\
& \text { - }\left(\left\{N O D_{E}\right\} \text { to }\left\{N_{\text {Room }}\right\}\right) \text {. }
\end{aligned}
$$

$N O D_{\text {Vorono }_{\text {Coridor }}}$ is the centroid Vorono $_{\text {Coridor }}$ polygons and similar, $N O D_{\text {Stair }}$ is the centroid of star polygons, $N O D_{\text {Elevator }}$ is the centroid of the platform of elevator polygons, $N O D_{R O O M}$ is the centroid of room polygons. Only $\left\{N O D_{E}\right\}=\{E\}$.

The research was divided into two stages. The first involved the segmentation of the public space. The second stage included the process of building a network model and generating routes. Upon the automatic generation of navigation network models, the results should be verified. Each edge of the network model should be embedded in the uniform space: $S_{\text {Corridor }}$ or $S_{\text {Room }}$. This means, for instance, that the sections of the network in the public space (corridor) should not intersect the space of the other ob- jects (rooms, stairs) $S_{U s e}$ Edges should not be very close to wall. Krūminaitè (2014) identified the minimal distance for $0.7 \mathrm{~m}$. Edges that do not meet these rules should be removed.

The final assessment of the generated models should be verified against the assessment of the shortest way (route, pathway) between two rooms on one floor in building. Figure $8 \mathrm{~b}$ presents this route which was proposed for result verification.

In each test (T1-T5), the execution methodology is similar, there are only changes in the initial set $P_{i}$.

\section{Results}

The results of the research were presented in graphic form and table data.

Indirect data from processing results spatial data are shown in Figure 9, based on data from test 4.

As a result of the research, various segmentations of the public space have been generated, as well as various navigation network models and various passage routes. The results of segmentation are shown in Figure 10. These are intermediate results and Figure 11 presents the final result showing five navigation network models and five roads between the two rooms.

The statistical data regarding the results is shown in Table 1 . The figures in the second column indicate the different number of elements of subsets $\left\{P_{i}\right\}$. These are figures showing whole sets of points and their subsets situated in the corridor space. The figures range from 28 points in test

Table 1. Description of the research results in the assumed tasks 1-5

\begin{tabular}{|l|c|c|c|c|c|}
\hline & $\begin{array}{c}\text { Number of } \\
\text { points in set } \\
\left\{P_{i}\right\} \text { in corridor } \\
\text { space }\end{array}$ & $\begin{array}{c}\text { Number of } \\
\text { segments in the } \\
\text { public space }\end{array}$ & $\begin{array}{c}\text { Number of } \\
\text { edges in the } \\
\text { network model }\end{array}$ & $\begin{array}{c}\text { Number of } \\
\text { nodes in the } \\
\text { network model }\end{array}$ & $\begin{array}{c}\text { Verify the } \\
\text { results }- \text { length } \\
\text { of the shortest } \\
\text { route [m] }\end{array}$ \\
\hline Test $1-\operatorname{model} 1,\left\{P_{1}\right\}=\{E\}$ & 37 & 32 & 125 & 106 & 54.1 \\
\hline Test $2-\operatorname{model} 2,\left\{P_{2}\right\}=\{W\}$ & 74 & 63 & 165 & 138 & 56.2 \\
\hline Test $3-$ model 3, $\left\{P_{3}\right\}=\{\{E\} \cup\{W\}$ & 111 & 83 & 219 & 157 & 57.6 \\
\hline Test $4-$ model $4,\left\{P_{4}\right\}=\{C\}$ & 28 & 39 & 135 & 113 & 56.6 \\
\hline Test $5-$ model $5,\left\{P_{5}\right\}=\{\{E\} \cup\{C\} \cup\{W\}$ & 139 & 135 & 269 & 196 & 58.2 \\
\hline
\end{tabular}

a)

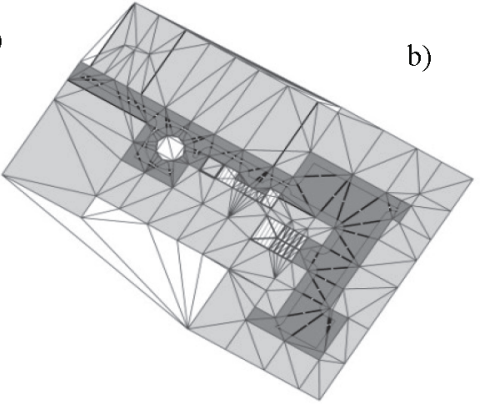

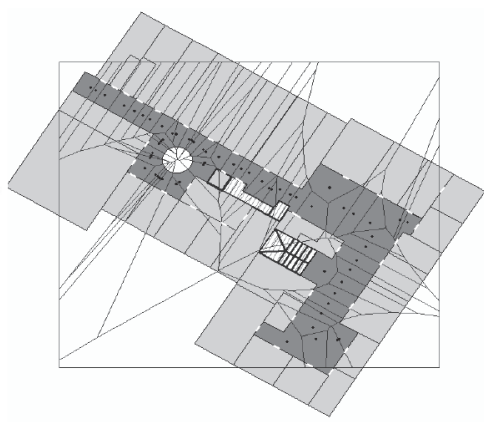

Figure 9. Segmentation of the public space: a) selection of points $\left\{P_{V}\right\}$, it is the middle sections of the edges of Delaunay Triangulation in $S_{C F}$; b) generation of Thiessen Polygons $\{$ Voronoi $\}$ based on points $\left\{P_{V}\right\}$; c) $S_{W h o l e}^{\text {New }}$ - result of the performed segmentation 


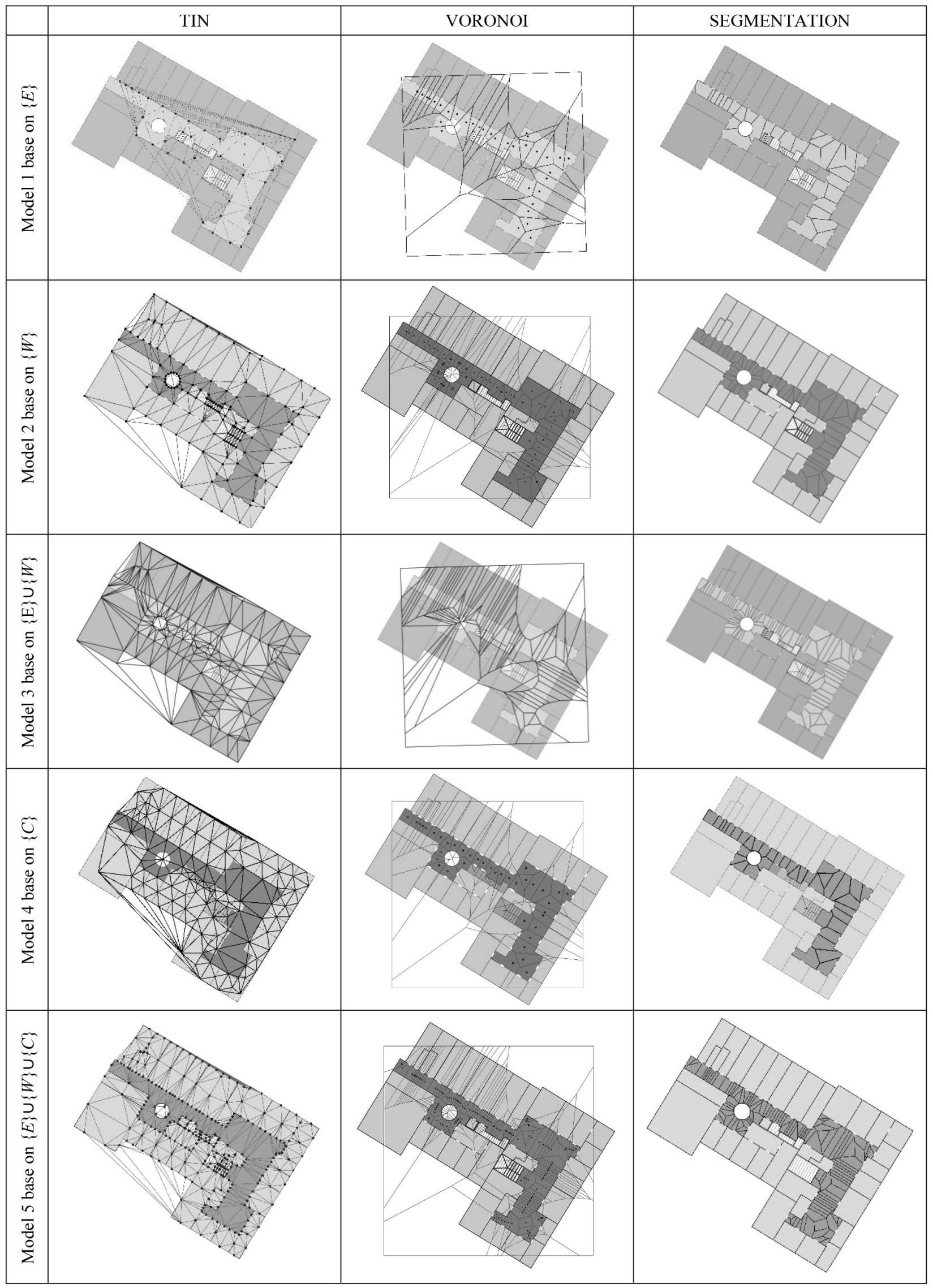

Figure 10. Graphic results of the first stage of the research involving the segmentation of the public space 


\begin{tabular}{|c|c|c|}
\hline & NAVIGATION NET & ROUTE \\
\hline 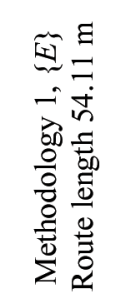 & & \\
\hline 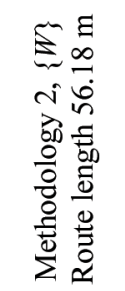 & & \\
\hline 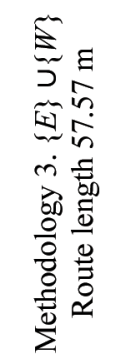 & & \\
\hline 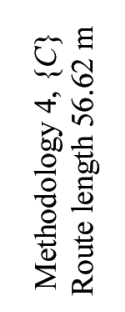 & & \\
\hline 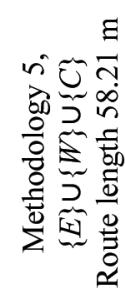 & & \\
\hline
\end{tabular}

Figure 11. Graphic results of the second stage of the research involving the production of the network models and the generation of routes 

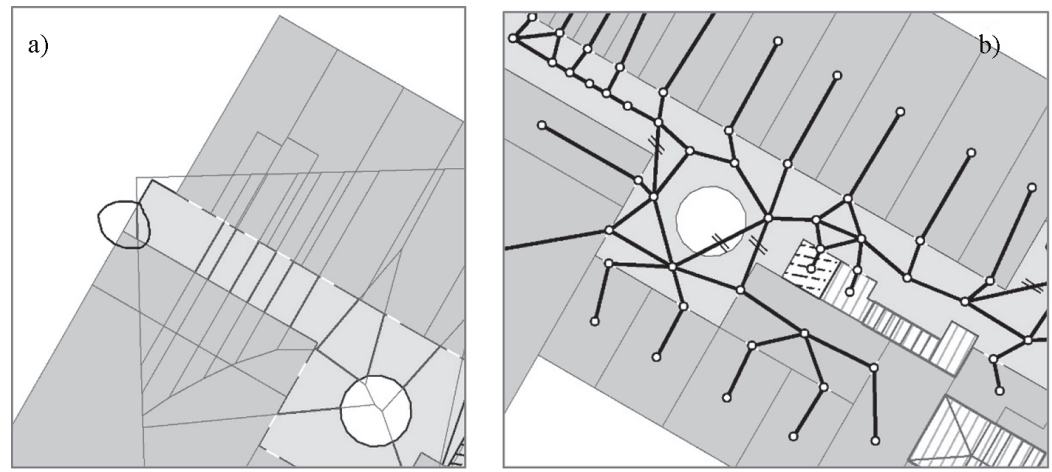

Figure 12. Image of the errors detected in the process of generating models with the use of methodology 1: a) the Voronoi diagram does not cover the entire space of the researched object; b) the model of navigation network goes across the open space between the two floors and near the wall, in pictures the edges are marked which have to be removed
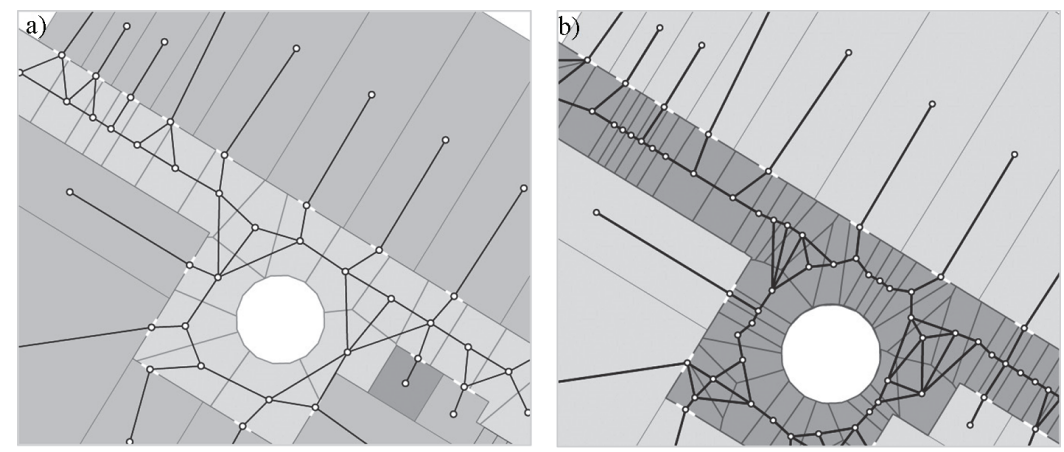

Figure 13. The topological lines connecting corridor segments to the room entrances: a) entry polygons were the size of the door hole (model 4 ); b) entry polygons were the size of $1 / 3$ the door hole (model 5 )

4 to 139 in test 5 . The number of the corridor segments obtained in successive tests is shown in column 3; the smallest number is 32 segments and the largest is 135 with set $\left\{P_{i}\right\}$ of 139 points. Various numbers of nodes and edges were obtained in the network model. The differences in the length of the generated routes are small.

In all solutions, segmentation on straight corridor fragments (in the north-western part of the corridor) runs perpendicular to the axis. In open space (in the eastern part of the corridor), all models are similar. Segmentation in five models differs in details.

\section{Discussion}

This study presents a methodology of generating models of road networks and identifies the optimum base set $\left\{P_{i}\right\}$ initiating an automatic process. The presented results indicate that network models using varied data sets $\left\{P_{i}\right\}$ are similar. Models differ by resolution, which means that with a small set of base points $\{P\}$, models are simplified, while with a large one $\left\{P_{i}\right\}$ they are fragmented. The generated network models do not intersect the open space between the two floors, except for the network produced using methodology 1 . The largest diversification of the network models occurs in the western side of the building, where the public space is extensive. The larger segmentation did not involve the shortening of the route between two given points. The length of the shortest routes increased with the expanding segmentation (Table 1). The shortest generated routes (2-5) are of different values of length, but the difference is insignificant and does not exceed 2 meters. The shortest routes run along the center of the corridor. They are not zigzagging. Only the route in the first model is not suitable for navigation. The other routes can be used for navigation before eliminating the same edge running near the walls.

The models generated with the use of test 1 should be interpreted separately. They contain two types of errors. In the first type of error, the Voronoi diagram (Thiessen Polygons) does not cover the entire area of the corridor (Figure 12a). The scope of the Voronoi polygons is smaller than the corridor area. The second type of errors is also important (presented in Figure 12b). One edge of the network model goes across the open space between the two floors and four edges run near the wall. These errors are not present in models which were generated from more points $\left\{P_{i}\right\}$.

When drawing conclusions from the presented solutions, one must observe that:

- Selection of base points for automatic construction of models should not be limited only to entry points $\{E\}$;

- A recommended set should contain points $\{W\}$; 
- A set with the maximum number of points $\{E\} \cup\{W\}$ $\cup\{C\}$ should not be used. This results in unnecessary details of the network and does not contribute to the minimization of the length of the generated routes;

- Using the functional space of a corridor $\mathrm{S}_{\mathrm{CF}}$ in the selection $\{E D G E\}_{T I N}$ limited the number of the generated points $\left\{P_{V}\right\}$ for the building segment. Points near the corridor walls near the recesses were eliminated. Thereby, the number of segments not perpendicular to the (virtual) corridor axis was minimized.

This thesis has been verified. Segmentation of corridors with various subsets $\left\{P_{i}\right\}$ runs in a similar manner, perpendicularly to the middle line of the corridor. Network models are similar. Results for various sets $\left\{P_{i}\right\}$ have different resolutions. In Model 2, $P_{2}=\{W\}$, corridor-to-room routes involve almost right angles. A similar situation occurs for a larger number of segments, e.g. in Model 5. For a smaller numbers of segments, e.g. Models 1 and 4, the angles are different than a right angle.

During the generation of topological relationships between layers with different geometry which were automatically generated, there were occasionally problems with topological consistency data. The points $\{E\}$ are not consistent with the borders of segments. The application Cgraph solved this problem. The algorithm changed the entry point $\{E\}$ to polygons (buffer). This solution can generate more lines from corridor segments to entry if the polygons $\{E\}$ are too large. Figure 13 presents these results: a) with a bigger buffer and b) with a smaller buffer. It should be discussed whether solution a) (Figure 13a) with the application of a larger buffer and, consequently with a larger number of generated edges, is more effective. Routes generated in these solutions will have a smaller number of angles close to straight angles. The minimum buffer value was applied in solution b) - Figure 13b. Thereby, the number of additional edges from segments to entry points $\{E\}$ was reduced.

If data are arranged topologically, then points $\{E\}$ are located exactly on the boundary edge of the segments (i.e. points $\{E\}$ are consistent with the boundaries of the segments). In this case, the algorithm in the Cgraph application, based on topological relations, generates single edges from entry $\{E\}$ to the segments. Furthermore, if more edges are required, the replacement of entry points $\{E\}$ with polygons (buffers) should be proposed in the Cgraph application.

In the presented solutions, a door-hole size buffer was used (Models 1, 2, 3, 4). In Model 5, a 1/3 door-hole size buffer was used (Model 5).

The analysis of the results shows that the adopted methodology is alternative to methodologies which employ the MAT algorithm (Lee 2004; Teo, Cho 2016). When comparing the results with other solutions (Krüminaite 2014; Bogusławski et al. 2016), one must observe that routes in the presented methodology are straighter and less zigzagging.

\section{Acknowledgements}

Conducted research and this publication was financed from the statutory project "Geoinformation in the theoretical, analytical and implementation aspect", No. 28.610.033300 for the years 2017-2020, carried out at the Faculty of Geodesy Geospatial and Civil Engineering, University of Warmia and Mazury in Olsztyn, Poland.

\section{Disclosure statement}

Authors do not have any competing financial, professional, or personal interests from other parties.

\section{References}

Afyouni, I.; Cyril, R.; Christophe, C. 2012. Spatial models for context-aware indoor navigation systems: A survey, Journal of Spatial Information Science 1(4): 85-123.

https://doi.org/10.5311/JOSIS.2012.4.73

Alattas, A. F.; Zlatanova, S.; Oosterom, P. V.; Chatzinikolaou, E.; Lemmen, C.; Li, K. J. 2017. Supporting indoor navigation using access rights to spaces based on combined use of IndoorGML and LADM models, ISPRS International Journal of Geo-Information 6(12): 384-416. https://doi.org/10.3390/ijgi6120384

Boeters, R.; Ohori, K. A.; Biljecki, F.; Zlatanova, S. 2015. Automatically enhancing CityGML LOD2 models with a corresponding indoor geometry, International Journal of Geographical Information Science 29(12): 2248-2268. https://doi.org/10.1080/13658816.2015.1072201

Bogusławski, P.; Mahdjoubi, L.; Zverovich, V.; Fadli, F. 2016. Automated construction of variable density navigable networks in a $3 \mathrm{D}$ indoor environment for emergency response, Automation in Construction 72: 115-128.

https://doi.org/10.1016/j.autcon.2016.08.041

Brassel, K. E.; Reif, D. 1979. A procedure to generate Thiessen polygons, Geographical Analysis 11(3): 215-222. https://doi.org/10.1111/j.1538-4632.1979.tb00695.x

Chew, L. P. 1987. Constrained Delaunay triangulations, in Proceedings of the $3^{\text {rd }}$ Annual Symposium on Computational Geometry, 1987, Waterloo, Ontario, Canada. ACM Press, 215-222. https://doi.org/10.1145/41958.41981

Cichociński, P. 2017. Modelowanie ewakuacji z budynków z wykorzystaniem analiz rastrowych [Modelling evacuation of buildings using raster analysis], Roczniki Geomatyki 15(4): 341-351.

Coleman, D. J.; Rajabifard, A.; Kolodziej, K. W. 2016. Expanding the SDI environment: comparing current spatial data infrastructure with emerging indoor location-based services, International Journal of Digital Earth 9(6): 629-647. https://doi.org/10.1080/17538947.2015.1119207

ESRI. 2018. ArcGIS online [online], [cited 10 May 2018]. Available from Internet: http://www.arcgis.com

Franz, G.; Mallot, H. A.; Wiener, J. M. 2005. Graph-based models of space in architecture and cognitive science - A comparative analysis, in Proceedings of $17^{\text {th }}$ International Conference on Systems Research, Informatics and Cybernetics (INTERSYMP-2005), 1-7 August 2005, Baden-Baden, Germany.

Gao, S.; Krogstie, J.; Thingstad, T.; Tran, H. 2017. An empirical study of the adoption of an indoor location-based service: Finding reading rooms, International Journal of Technology and Human Interaction 13(2): 70-88. https://doi.org/10.4018/IJTHI.2017040105 
Hahmann, S.; Jakob, M.; Bernd, R.; Lauer, J.; Zipf, A. 2018. Routing through open spaces - a performance comparison of algorithms, Geo-spatial Information Science 21(3): 247-256. https://doi.org/10.1080/10095020.2017.1399675

Hilsenbeck, S.; Bobkov, D.; Schroth, G.; Huitl, R.; Steinbacg, E. 2014. Graph-based data fusion of pedometer and WiFi measurements for mobile indoor positioning, in Proceedings of the 2014 ACM International Joint Conference on Pervasive and Ubiquitous Computing, 2014, 147-158.

https://doi.org/10.1145/2632048.2636079

Joan-Arinyo, R.; Pérez-Vidal, L.; Gargallo-Monllau, E. 1997. An adaptive algorithm to compute the medial axis transform of 2-d polygonal domains, in D. Roller, P. Brunet (Eds.). CAD systems development. Tools and methods. Berlin Heidelberg: Springer, 283-298.

https://doi.org/10.1007/978-3-642-60718-9_20

Kaliszczuk, L. 2013. Wizualizacja 3D budynku Wydziału Geodezji $i$ Gospodarki przestrzennej UWM w Olsztynie w Google Earth [3D visualization of a building of the Faculty of Geodesy and Spatial management UWM in Olsztyn in Google Earth]: Diploma thesis. Katedra Geodezji Szczegółowej, UWM Olsztyn.

Krūminaite, M. 2014. Space subdivision for indoor navigation: Master thesis. Delft University of Technology.

Lee, J. 2004. A spatial access-oriented implementation of a 3-D GIS topological data model for urban entities, Geoinformatica 8(3): 237-264.

https://doi.org/10.1023/B:GEIN.0000034820.93914.d0

Lee, J. 2007. A three-dimensional navigable data model to support emergency response in microspatial built-environments, Annals of the Association of American Geographers 97(3): 512-529. https://doi.org/10.1111/j.1467-8306.2007.00561.x

Lewandowicz, E. 2014. Network models of 2D and 3D cadastral data. Selection and peer-review under responsibility of the Vilnius Gediminas Technical University.

Lewandowicz, E. 2015. 3D cadastre, building 3D models with navigation network, in New challenges for land information systems in the light of European standards. Croatian Information Technology Society, GIS Forum. Zagreb, Croatia.

Lewandowicz, E.; Packa, A.; Kondratowicz, S. 2013. Przekształcanie danych topologicznych, geometrycznych i atrybutowych GIS do modeli analitycznych [Conversion topological geometric and attribute GIS data to analytical models], Acta Universitatis Lodziensis, Folia Geographica Socio-Oekonomica 14: 33-44.

Lin, Z.; Xu, Z.; Hu, D.; Li, W. 2017. Hybrid spatial data model for indoor space: Combined topology and grid, ISPRS International Journal of Geo-Information 6(11): 343. https://doi.org/10.3390/ijgi6110343

Lisowski, P.; Lewandowicz, E. 2016. Przetwarzanie i wizualizacje zapisów sąsiedztwa danych katastralnych w strukturach grafowych [Processing and visualization of neighborhood cadastral data notations in the graph structures], Roczniki Geomatyki 14(4): 487-496.

Lisowski, P.; Lewandowicz, E. 2018. Metodyka zapisu topologicznego modelu struktur katastralnych w grafowych bazach danych [Methodology of storing topological models of cadastral structures in graph databases], Roczniki Geomatyki 16(1): 45-54.

Liu, L.; Zlatanova, S. 2015. An approach for indoor path computation among obstacles that considers user dimension, ISPRS International Journal of Geo-Information 4(4): 2821-2841. https://doi.org/10.3390/ijgi4042821

Mortari, F.; Zlatanova, S.; Liu, L.; Clementini, E. 2014. Improved geometric network model (IGNM): A novel approach for deriving connectivity graphs for indoor navigation, ISPRS Annals of the Photogrammetry, Remote Sensing and Spatial Information Sciences, Vol. II-4.

Prinz, F. B.; Cern, J.-H. 1988. Geometric abstractions using medial axis transformation. Pittsburgh: Carnegie Mellon University, Research Showcase @ CMU.

Staats, B. R.; Diakit, A. A.; Voute, R. L.; Zlatanova, S. 2017. Automatic generation of indoor navigable space using a point cloud and its scanner trajectory, ISPRS Annals of the Photogrammetry, Remote Sensing and Spatial Information Sciences, Vol. IV-2/W4.

Stoffel, E. P.; Lorenz, B.; Ohlbach, H. J. 2007. Towards a semantic spatial model for pedestrian indoor navigation, in Advances in Conceptual Modeling - Foundations and Applications. Lecture Notes in Computer Science, Vol. 4802. Berlin, Heidelberg: Springer, 328-337.

https://doi.org/10.1007/978-3-540-76292-8_39

Tang, S. J.; Zhu, Q.; Wang, W. W.; Zhang, Y. T. 2015. Automatic topology derivation from IFC building model for in-door intelligent navigation, in Remote Sensing and Spatial Information Sciences, Vol. XL-4/W5.

Teo, T. A.; Cho, K. H. 2016. BIM-oriented indoor network model for indoor and outdoor combined route planning, Advanced Engineering Informatics 30(3): 268-282. https://doi.org/10.1016/j.aei.2016.04.007

Wallgrün, J. O. 2004. Autonomous construction of hierarchical Voronoi-based route graph representations, in Proceedings of the $4^{\text {th }}$ International Conference on Spatial Cognition: Reasoning Action, Interaction, 2004, 413-433.

Wei, L.; Chen, Y. H.; Li, L.; Fu, H. M.; Wei, L. 2012. Application of Thiessen polygon algorithm in cellular network simulation system, Advanced Materials Research 532-533: 1851-1856. https://doi.org/10.4028/www.scientific.net/AMR.532533.1851

Whiting, E. J. 2006. Geometric, topological \& semantic analysis of multi-building floor plan data: Doctoral dissertation. Massachusetts Institute of Technology, USA.

Xu, M.; Hijazi, I.; Mebarki, A.; Meouche, R. E.; Abunemeh, M. 2016b. Indoor guided evacuation: TIN for graph generation and crowd evacuation, Geomatics, Natural Hazards and Risk 7(Sup 1): 47-56.

https://doi.org/10.1080/19475705.2016.1181343

Xu, M.; Wei, S.; Zlatanova, S. 2016a. An indoor navigation approach considering obstacles and space subdivision of $2 \mathrm{D}$ plan, in ISPRS International Archives of the Photogrammetry, Remote Sensing and Spatial Information Sciences, XLI-B4, 339-346.

Yan, J.; Zlatanowa, S.; Diakite, A. 2018. Seamless pedestrian navigation in indoor/outdoor large spaces with no clear patterns for movement. $3 \mathrm{D}$ geoinformation: $\mathrm{PhD}$ research proposal. Delft University of Technology.

Yang, L.; Sun, X.; Zhu, A.; Chi, T. 2017. A multiple ant colony optimization algorithm for indoor room optimal spatial allocation, ISPRS International Journal of Geo-Information 6(6): 161. https://doi.org/10.3390/ijgi6060161

Yang, L.; Worboys, M. F. 2015. Generation of navigation graphs for indoor space, International Journal of Geographical Information Science 29: 1737-1756. https://doi.org/10.1080/13658816.2015.1041141

Zhu, Q.; Li, Y.; Xiong, Q.; Zlatanova, S.; Ding, Y.; Zhang, Y.; Zhou, Y. 2016. Indoor multi-dimensional location GML and its application for ubiquitous indoor location services, ISPRS International Journal of Geo-Information 5(12): 220.

https://doi.org/10.3390/ijgi5120220 